\title{
Serum Vitamin D and Interleukin-6 Levels in Patients with Preeclampsia and Healthy Pregnant Women
}

Negin Rezavand (MD)

Department of Obstetrics and Gynecology, Fertility and Infertility

Research Center, Kermanshah University of Medical Sciences, Kermanshah, Iran

Asad Vaisi-Raygani $(\mathrm{PhD})$

Department of Clinical Biochemistry, Fertility and Infertility Research Center, Kermanshah University of Medical Sciences, Kermanshah, Iran Firozeh Vaisi (MD)

Department of Obstetrics and Gynecology, Fertility and Infertility

Research Center, Kermanshah University of Medical Sciences, Kermanshah, Iran

Maryam Zangneh (MD)

Department of Obstetrics and Gynecology, Fertility and Infertility Research Center, Kermanshah University of Medical Sciences, Kermanshah, Iran

Azin Hoshiar (MD)

Department of Obstetrics and Gynecology, Fertility and Infertility Research Center, Kermanshah

University of Medical Sciences, Kermanshah, Iran

Fariborz Bahrehmand (PhD) Department of Clinical Biochemistry, Fertility and Infertility Research Center, Kermanshah University of Medical Sciences, Kermanshah, Iran

Amir Kiani (PhD)

Department of Pharmacology and Toxicology, Kermanshah University of Medical Sciences, Kermanshah, Iran

Gholamabass Dinarvand (MSc) Department of Biochemistry, Faculty member of Abadan School of Medical Sciences, Abadan, Iran

Corresponding author: Assad VaisiRaygani

Email: avaisiraygani@gmail.com Tel: +989183331207

Address: Fertility and Infertility Research Center, Kermanshah University of Medical Sciences, Kermanshah, Iran

Received : 07 Oct 2015

Revised: 09 Dec 2015

Accepted: 01 Feb 2016
ABSTRACT

Background and objective: Nutritional factors and activation of inflammatory pathways are thought to be involved in pathogenesis of preeclampsia in pregnant women. The present study aimed to compare the serum levels of vitamin I) and interleukin-6 in healthy pregnant women with those of preeclampsia ones.

Methods: This case-control study was performed on 120 healthy pregnant women and 120 women with preeclampsia referred to Imam Reza Hospital in Kermanshah. The serum levels of vitamin I and IL-6 were measured by ELISA method. The data was analyzed by SPSS software (version 20) using independent t-test, the P-value of $<0.05$ was considered as statistically significant.

Results: There was no statistically significant difference between the mean level of vitamin $\mathrm{D}$ in the patients $(37.64 \pm 29.50 \mathrm{ng} / \mathrm{ml})$ and the controls $(40.06 \pm 33.20 \mathrm{ng} / \mathrm{ml})$. the serum level of IL-6 in patients with preeclampsia $(21.71 \pm 32.24 \mathrm{pg} / \mathrm{ml})$ was significantly higher compared to that of control group $(15.04 \pm 20.6 \mathrm{pg} / \mathrm{ml})(\mathrm{P}<0.001)$.

Conclusion: Based on the findings of this study, inflammatory factors and cytokines such as IL-6 can be considered as risk factor for preeclampsia. However, more studies with larger sample sizes are required to further evaluate the association of vitamin D levels and risk of preeclampsia.

Keywords: Pregnancy, Pre-Eclampsia, Vitamin I, Interleukin-6.

This paper should be cited as: Rezavand N, Vaisi-Raygani A, Vaisi F, Zangneh M, Hoshiar A, Bahrehmand F, Kiani A, Dinarvand GH[Serum Vitamin D and Interleukin-6 Levels in Patients with Preeclampsia and Healthy Pregnant Women]. mljgoums. 2016; 10(4): $12-17$ 


\section{INTRODUCTION}

Preeclampsia is a systemic pregnancy disorder that affects 5 to $7 \%$ of all pregnancies worldwide and remains a leading cause of morbidity and mortality in mothers, fetuses and infants. It is the third most common cause of maternal mortality in the world (1) and the second most common cause of maternal mortality in Iran. Preeclampsia is responsible for about $18 \%$ of all maternal deaths in the country (2). Preeclampsia is defined as high blood pressure (more than 140/90 $\mathrm{mmHg}$ ) for the first time and proteinuria of $\geq 0.3$ grams in a 24-hour urine specimen (or a urine dipstick protein of $1+$ ) that occur after 20 weeks of pregnancy $(3,4)$. Although the exact cause of preeclampsia remains unknown, several pathophysiologic mechanisms such as endothelial dysfunction, oxidative stress, activation of inflammatory pathways, and activation of renin-angiotensin system have been suggested (5). Many studies have evaluated the role of inflammation in the pathogenesis of preeclampsia $(6,7)$. The main role of cytokines in the pathogenesis of preeclampsia is causing endothelial dysfunction in the mother's vascular system (8). Among all inflammatory markers, a serum concentration of interleukin-6 (IL-6) is increased in patients with preeclampsia compared to healthy pregnant mothers (9-11).

The pathogenesis of preeclampsia consists of a number of biological processes including impaired immune function, implantation of the placenta, excessive inflammation and high blood pressure that may be influenced by vitamin D, either directly or indirectly (12-15). Epidemiological studies suggest a strong association between low vitamin D levels and preeclampsia $(16,17)$. Optimal levels of vitamin D and suppression of immune cells improve blood flow in the vessels within the placenta. Therefore, vitamin D deficiency due to poor permeability of vessels within the placenta can trigger the early stages of preeclampsia (17). Cohort studies on nulliparous pregnant women showed a $27 \%$ reduction in the risk of preeclampsia in women who received vitamin D supplements (18). Clinical and biochemical studies show that several endothelial cell dysfunctions are associated with increased levels of inflammatory factors and cytokines that may be the primary cause of preeclampsia (5). Thus, this study aimed to compare serum levels of vitamin D and IL-6 in pregnant women with preeclampsia and healthy pregnant women.

\section{MATERIAL AND METHODS}

This case-control study was performed on 240 pregnant women (age range 20-35 years) ,with gestational age of 28-40 weeks, who were referred to the obstetric clinic at Imam Reza Hospital of Kermanshah University of Medical Sciences in 2014. All preeclamptic women referred to the hospital were included in the study except those with multiple birth pregnancies, history of hypertension, diabetes, cardiovascular and renal diseases. The control group included first-time healthy singleton pregnant women with no history of systemic diseases, drug use, smoking and addiction. Data collection was carrid out using a questionnaire with the following sections: demographic information, parity, gestational age, weight, height and body mass index (BMI). The laboratory information included the levels of protein in urine, serum levels of vitamin D and IL-6, and blood pressure (systolic and diastolic). The commercial ELISA kits were used to measure serum vitamin D (Imnundiagnostic Cat No; k2108KD with $1 \mathrm{ng} / \mathrm{mL}$ sensitivity) and IL-6 (EuroBioSciences platinum with $0.92 \mathrm{pg} / \mathrm{mL}$ sensitivity) levels. The obtained data was analyzed by SPSS software (version 20) using independent t-test. The P-value of less than 0.05 was considered as statistically significant.

\section{RESULTS}

In this study, 120 women with preeclampsia (case group) and 120 healthy pregnant women (control group) were evaluated. The average age of mothers in the case and control groups was 30.85 and 28.7 years, respectively. The mean of gestational age in women with preeclampsia and healthy women was 34.4 and 33.82 years, respectively. There was no statistical difference between the mean BMI of the preeclampsia group and the controls $(P=0.32)$. BMI of women with severe preeclampsia was significantly higher than the controls $(\mathrm{P}<0.001)$ (Table 1). The mean blood pressure of the patients with preeclampsia $(13.98 / 90.70 \mathrm{mmHg})$ was significantly higher than the controls $(11.56 / 71.37 \mathrm{mmHg})(\mathrm{p}<0.001)$. 
The mean blood pressure of pregnant women with severe preeclampsia was significantly higher compared to other participants $(\mathrm{P}<0.001)$. Overall, 82 cases had proteinuria $1+$ and trace, and 20 cases had proteinuria 2+ or higher. All participants with severe preeclampsia had proteinuria $\geq 2+$, while $19.6 \%$ of them with mild preeclampsia had proteinuria $\geq 2+$ (Table 1$)$.

The mean level of vitamin $\mathrm{D}$ in pregnant women with preeclampsia was lower
$(\mathrm{P}=0.55)($ Table 2$)$. The mean serum level of IL-6 in the case group was significantly high compared to the control group $(\mathrm{p}<0.001)$ (Table 2, Figure

The mean serum level of vitamin D in women with severe preeclampsia was lower compared to patients with mild preeclampsia $(\mathrm{P}=0.5)$. The mean serum level of IL-6 in participants with severe preeclampsia was high compared to subjects with mild preeclampsia $(\mathrm{P}=0.1)$ (Table 3).

Table 1- Comparison of BMI, blood pressure and proteinuria between patients with mild and severe preeclampsia

\begin{tabular}{|c|c|c|c|}
\hline Variable & Mild preeclampsia & Severe preeclampsia & P-value \\
\hline BMI $\left(\mathrm{kg} / \mathrm{m}^{2}\right)$ & $28.9 \pm 2.8$ & $33.7 \pm 4.38$ & $<0.001$ \\
\hline Blood pressure (mm Hg) & & & \\
\hline $\begin{array}{l}\text { Systolic } \\
\text { Diastolic }\end{array}$ & $\begin{array}{c}13.67 \pm 1.1 \\
8.9 \pm 7.04\end{array}$ & $\begin{array}{c}15.7 \pm 0.82 \\
9.55 \pm 2.3\end{array}$ & $<0.001$ \\
\hline $\begin{array}{l}\text { Proteinuria }[\mathrm{n}(\%)] \\
\text { Cases with } 1+\& \text { trace } \\
\text { Cases with } 2+\text { or higher }\end{array}$ & $\begin{array}{l}80.4 \%(n=82) \\
19.6 \%(n=20)\end{array}$ & $\begin{array}{c}\text { none } \\
100 \%(n=18)\end{array}$ & $<0.001$ \\
\hline
\end{tabular}

Table 2-Comparison of Vitamin D and IL-6 levels between the two study groups

\begin{tabular}{cccc}
\hline & Control & preeclampsia & P-value \\
\hline Vitamin D $(\mathbf{n g} / \mathrm{ml})$ & $\mathbf{4 0 . 0 6} \pm \mathbf{3 3 . 2}$ & $\mathbf{3 7 . 6 4} \pm \mathbf{2 9 . 5 0}$ & $\mathbf{0 . 5 5}$ \\
IL 6 $(\mathrm{pg} / \mathrm{ml})$ & $\mathbf{1 5 . 0 4} \pm \mathbf{2 8 . 6}$ & $\mathbf{2 1 . 7 1} \pm 32.24$ & $<0.001 *$ \\
\hline
\end{tabular}

Mann-Whitney Test, NPar Tests, T-Test

Table 3- Comparison of IL-6 and vitamin D levels between severe and mild cases of preeclampsia

\begin{tabular}{cccc}
\hline & Mild preeclampsia & Severe preeclampsia & P-value \\
\hline Vitamin D(ng/ml) & $38.38 \pm 30.7$ & $33.63 \pm 21.6$ & 0.5 \\
IL 6(pg/ml $)$ & $20.39 \pm 32.57$ & $29.1 \pm 30.1$ & 0.1 \\
\hline
\end{tabular}

Figure 1- Comparison of IL-6 levels between severe and mild cases of preeclampsia

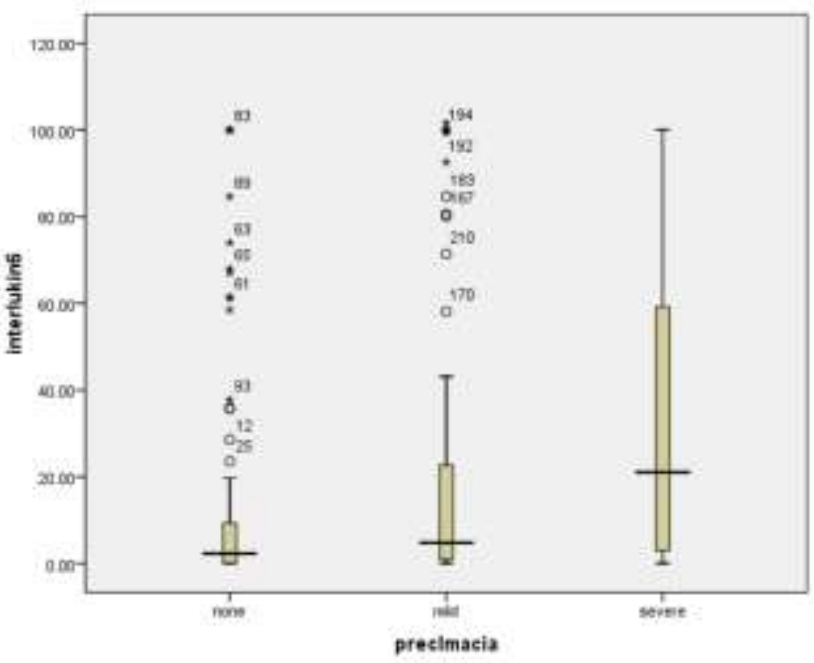




\section{DISCUSSION}

According to the findings, the mean serum level of vitamin $\mathrm{D}$ in women with preeclampsia was lower compared to the controls. There was no statistically significant difference in the serum levels of vitamin D between severe and mild cases of preeclampsia. This suggests the lack association of vitamin D levels in patients with the severity of preeclampsia. A serum level of IL-6 in patients with preeclampsia was significantly higher compared to the controls. Moreover, there was a significant association between high BMI and increased risk of severe preeclampsia. IL-6 is a pro-inflammatory cytokine produced by mononuclear phagocytes, endothelial cells, fibroblasts and T-cells. It is involved in immune activation and regulation of tumor necrosis factor production by arterial wall. Afshari reported increased levels of IL-6 in women with preeclampsia (19). Teran (20) and Hentschke (21) also reported increased plasma levels of cytokines such as IL-6 (its soluble receptor) in pregnant women with preeclampsia. In the present study, there was a significant correlation between increased concentration of IL-6 and preeclampsia. Consistent with this finding, Lau showed that the increased levels of TNF- $\alpha$ and IL- 6 and IL-10 are associated with both mild and severe preeclampsia (22). In this study, a significant correlation was observed between increased IL-6 levels and preeclampsia. However, Ozler showed no significant difference in mean serum levels of IL-6 and TNF- $\alpha$ between healthy pregnant women and mild or severe cases of preeclampsia (23). Meanwhile, Olusi reported an increased level of IL-6 and TNF in normal pregnant women (24). The Inconsistency between the findings of the mentioned studies may be due to the differences in study design, sample size, methods' sensitivity, type of samples, and sample collection method.

Bodnar reported that an increased vitamin D level to $22 \mathrm{ng} / \mathrm{ml}$ reduces the risk of preeclampsia by 2 -fold and concluded that vitamin $\mathrm{D}$ deficiency in mothers may be an independent risk factor for preeclampsia (17). Study of Abedi et al. also showed that vitamin $\mathrm{D}$ deficiency is significantly associated with risk of preeclampsia. Considering the low level of vitamin D due to poor lifestyle, daily intake of $400 \mathrm{IU}$ vitamin D is recommended to pregnant women (25). In another study,
Ghomian also observed a clear association between vitamin $\mathrm{D}$ deficiency and risk of severe preeclampsia. Vitamin D supplementation may be effective in prevention of preeclampsia (26). The mentioned study reported that vitamin D3 does not affect gene expression, endothelial growth factor, vascular endothelial alterations and the underlying mechanisms of preeclampsia, which is inconsistent with the findings of the present study (27). Study of seasonal patterns in preeclampsia showed the lowest incidence in summer, when there is plenty of sunlight with serum vitamin $\mathrm{D}$ concentrations at their peak $(28,29)$. However, some studies showed no association between vitamin $\mathrm{D}$ status and risk of preeclampsia (30-32). Study of $\mathrm{Xu}$ et al. reported a significant relationship between elevated levels of IL-6 and vitamin D deficiency, and the risk of preeclampsia (33). Although the present study found significantly increased levels of IL-6 in patients with preeclampsia, no significant relationship was observed between preeclampsia and vitamin D level.

In the present study, low vitamin D levels were observed in both groups that could be due to insufficient exposure of these women to sunlight. IL-6 levels were significantly higher in women with preeclampsia, which indicates the role of inflammatory factors and cytokines in the pathogenesis of preeclampsia.

\section{CONCLUSION}

Based on the findings of this study, inflammatory factors and cytokines such as IL6 can be considered as risk factors for preeclampsia. Moreover, there is no significant association between vitamin D levels in pregnant women and risk of preeclampsia.

\section{ACKNOWLEDGMENTS}

The authors would like to thank the Deputy of Research and Technology at Kermanshah University of Medical Sciences, all patients, and staff of Imam Reza Hospital in Kermanshah for their cooperation in this study.

\section{CONFLICT OF INTEREST}

The authors declare no conflicts of interest regarding this manuscript. 


\section{REFERENCES}

1. Wagner LK. Diagnosis and management of preeclampsia. Am Fam Physician. 2004; 70(12): 231724.

2. Ministry of Health and Medical Education Research and Technology Division Public Relations Department. Report on Health Research in the Islamic Republic of Iran. Mothers' health office annual report. 2006.

3. Villar J, Carroli G, Wojdyla D, Abalos E, Giordano D, Ba'aqeel $\mathrm{H}$, et al. Preeclampsia, gestational hypertension and intrauterine growth restriction, related or independent conditions? Am J Obstet Gynecol. 2006; 194(4): 921-931.

4. National High Blood Pressure Education Program Working Group on High Blood Pressure in Pregnancy. Report of the National High Blood Pressure Education Program Working Group on High Blood Pressure in Pregnancy. Am J Obstet Gynecol. 2000; 183(1): S1-22.

5. Salimi S, Mokhtari M, Yaghmaei M, Jamshidi M, Naghavi A. Association of angiotensin-converting enzyme intron 16 insertion/deletion and angiotensin II type 1 receptor A1166C gene polymorphisms with preeclampsia in South East of Iran. J Biomed Biotechnol. 2011; 941515. DOI: 10.1155/2011/941515.

6. Xie C, Yao MZ, Liu JB, Xiong LK. A meta-analysis of tumor necrosis factor-alpha, interleukin-6, and interleukin-10 in preeclampsia. Cytokine. 2011; 56(3): 550-559. doi: 10.1016/j.cyto.2011.09.021.

7. Darmochwal-Kolarz D, Rolinski J, LeszczynskaGorzelak B, Oleszczuk J. The expressions of intracellular cytokines in the lymphocytes of preeclamptic patients. Am J Reprod Immunol. 2002; 48(6): $\quad 381-386 . \quad$ DOI: $10.1034 / j .1600-$ 0897.2002.01089.x

8. Conrad KP, Miles TM, Benyo DF. Circulating levels of immunoreactive cytokines in women with preeclampsia. Am J Reprod Immunol. 1998; 40(2): 102111.

9. Bernardi F, Guolo F, Bortolin T, Petronilho F, DalPizzol F. Oxidative stress and inflammatory markers in normal pregnancy and preeclampsia. J Obstet Gynaecol Res. 2008; 34(6): 948-51. doi: 10.1111/j.14470756.2008.00803.x.

10. Singh A, Sharma D, Raghunandan C, Bhattacharjee J. Role of inflammatory cytokines and eNOS gene polymorphism in pathophysiology of pre-eclampsia. Am J Reprod Immunol. 2010; 63(3): 244-51. doi: 10.1111/j.1600-0897.2009.00781.x.

11. Kalinderis M, Papanikolaou A, Kalinderi $\mathrm{K}$, Ioannidou E, Giannoulis C, Karagiannis V, et al. Elevated serum levels of interleukin-6, interleukin-1 beta and human chorionic gonadotropin in pre-eclampsia. Am J Reprod Immunol. 2011; 66(6): 468-75. doi: 10.1111/j.1600-0897.2011.01019.x.

12. Cardus A, Parisi E, Gallego C, Aldea M, Fernandez E, Valdivielso JM. 1, 25 Dihydroxyvitamin D3 stimulates vascular smooth muscle cell proliferation through a VEGF-mediated pathway. Kidney Int. 2006; 69(8): 13771384.

13. Evans KN, Bulmer JN, Kilby MD, HewisonM. Vitamin $D$ and placentaldecidual function. J Soc Gynecol Investig. 2004; 11(5): 263-271.
14. Hewison M. Vitamin D and immune function: an overview. Proc Nutr Soc. 2012; 71(1): 50-61. doi: 10.1017/S0029665111001650.

15. Li YC, Kong J, Wei M, Chen ZF, Liu SQ, Cao LP. 1,25 Dihydroxyvitamin D3 is a negative endocrine regulator of the renin-angiotensin system. J Clin Invest. 2002; 110(2): 229-238.

16. Robinson CJ, Alanis MC, Wagner CL, Hollis BW, Johnson DD. Plasma 25-hydroxyvitamin D levels in early-onset severe preeclampsia. Am J Obstet Gynecol. 2010; 203(4): 366. e 1-6. doi: 10.1016/j.ajog.2010.06.036.

17. Bodnar LM, Catov JM, Simhan HN, Holick MF, Powers RW, Roberts JM. Maternal vitamin D deficiency increases the risk of preeclampsia. J Clin Endocrinol Metab. 2007; 92(9): 3517-22.

18. Haugen M, Brantsaeter AL, Trogstad L, Alexander J, Roth C, Magnus P, et al. Vitamin D supplementation and reduced risk of preeclampsia in nulliparous women. Epidemiology. 2009; 20(5): 720-26.

19. Afshari JT, Ghomian N, Shameli A, Shakeri M, Fahmidehkar MA, Mahajer E. Determination of Interleukin-6 and Tumor Necrosis Factor-alpha concentrations in Iranian-Khorasanian patients with preeclampsia. BMC Pregnancy and Childbirth. 2005; 5:14. DOI:10.1186/1471-2393-5-14.

20. Teran E, Escudero C, Moya W, Flores M, Vallance P. Elevated $C$-reactive protein and pro-inflammatory cytokines in Andean women with pre-eclampsia. Int $\mathrm{J}$ of Gynecol and Obst. 2001; 75(3): 243-49.

21. Hentschke MR, Lucas LS, Krauspenhar B, Raisa P F, Sussela AO, Berlesi F, et al. Increased levels of the soluble receptor of Interleukin-6 in patients with preeclampsia compared to normotensive pregnant women. Scientia Medica. 2014; 23(4): 121-6.

22. Lau SY, Guild SJ, Barrett CJ, Chen Q, McCowan L, Jordan V, et al. Tumor necrosis factor-alpha, interleukin6, and interleukin-10 levels are altered in preeclampsia: a systematic review and meta-analysis. Am J Reprod Immunol. 2013; 70(5): 412-427.

23. Ozler A, Turgut A, Sak ME, Evsen MS, Soydinc HE, Evliyaoglu O, et al. Serum levels of neopterin, tumor necrosis factor-alpha and Interleukin-6 in preeclampsia: relationship with disease severity. Eur Rev Med Pharmacol Sci. 2012; 16(12): 1707-12.

24. Olusi SO, Diejomaoh M, Omu A, Abdulaziz A, Prabha $\mathrm{K}$, George S. Interleukins in preeclampsia. Annals of Saudi Medicine. 2000; 20(1): 4-8.

25. Abedi $\mathrm{P}$, Mohaghegh $\mathrm{Z}$, Afshary $\mathrm{P}$, Latifi M. The relationship of serum vitamin $D$ with pre-eclampsia in the Iranian women. Matern Child Nutr. 2014; 10(2): 20612. DOI: $10.1111 / \mathrm{mcn} .12058$

26. Ghomian N, Lotfalizadeh M, Movahedian A. Comparative study of serum vitamin D levels in pregnant women with severe preeclampsia and healthy pregnant women. Journal of Midwifery and Women's infertility. 2015; 18(140): 1-6.

27. Fischer D, Schroer A, Lüdders D, Cordes T, Bücker $\mathrm{B}$, Reichrath J, et al. Metabolism of vitamin D3 in the placental tissue of normal and preeclampsia complicated pregnancies and premature births. Clin Exp Obstet Gynecol. 2007; 34(2):80-4. 
28. Bodnar LM, Catov JM, Roberts JM. Racial/ethnic differences in the monthly variation of preeclampsia incidence. Am J Obstet Gynecol. 2007; 196(4): 324 e15.

29. TePoel MR, Saftlas AF, Wallis AB. Association of seasonality with hypertension in pregnancy: a systematic review. J Reprod Immunol. 2011; 89(2): 140-52.

30. Shand AW, Nassar N, Von Dadelszen P, Innis SM, Green TJ. Maternal vitamin D status in pregnancy and adverse pregnancy outcomes in a group at high risk for pre-eclampsia. BJOG. 2010; 117(13): 1593-8.
31. Powe CE, Seely EW, Rana S, Bhan I, Ecker J, Karumanchi SA, et al. First trimester vitamin D, vitamin D binding protein, and subsequent preeclampsia. Hypertension. 2010; 56(4): 758-63.

32. Yu CK, Ertl R, Skyfta E, Akolekar R, Nicolaides $\mathrm{KH}$. Maternal serum vitamin D levels at 11-13 weeks of gestation in preeclampsia. J Hum Hypertens. 2013; 27(2): 115-8.

33. $\mathrm{Xu} \mathrm{L}$, Lee $\mathrm{M}$, Jeyabalan $\mathrm{A}$, Roberts JM. The relationship of hypovitaminosis $D$ and $I L-6$ in preeclampsia. Am J Obstet Gynecol. 2014; 210(2): 149.e1-7. 